\title{
Optimasi Decision Support System (DSS) Pemilihan Paket Layanan Internet Prabayar Dengan Metode ANP
}

\author{
Asbon Hendra Azhar, Ratih Adinda Destari \\ Universitas Potensi Utama \\ KL.Yos Sudarso Km. 6,5 No.3A Telp (061) 6640525 \\ asbon.upu@gmail.com, adindaalkarim0384@gmail.com
}

\begin{abstract}
At this time there are so many Internet packages provided by companies in the telecommunications sector to help facilitate Android users in accessing the Internet. Android users using this Internet package are for the purposes of social media, chatting, browsing, streaming and downloading where Android users will feel incomplete if they do not use the Internet package because in terms of finance it is most cost effective compared to using regular pulses. The Internet is currently one of the main alternatives in meeting all needs, namely Information and Education needs that provide positive value for all people. The number of operators offering Internet packages will certainly make it difficult for consumers to make the right choice according to their wishes and criteria. To overcome these problems, a system is made that will make decision making easier for choosing an Internet service package, one of which is the decision support system to help the community choose the best Internet service package. The method used in this study is the ANP Method. With the ANP method, it is expected to help the community in determining which alternatives will be chosen as a final decision in the selection of Internet Packages as needed
\end{abstract}

Keywords: ANP, SPK, Prepaid Internet Service Package, DSS, Criteria.

\begin{abstract}
Abstrak
Pada saat ini sangat banyak sekali paket Internet yang disediakan oleh perusahaan di bidang telekomunikasi dalam membantu memudahkan pengguna Android dalam mengakses Internet. Pengguna Android menggunakan paket Internet ini adalah untuk keperluan sosial media, chatting, browsing, streaming dan download dimana pengguna Android akan merasa tidak lengkap jika tidak menggunakan paket Internet karena dari segi keuangan paling hemat biayanya dibandingkan dengan menggunakan pulsa reguler. Internet pada saat ini merupakan salah satu alternatif utama dalam memenuhi segala kebutuhan yaitu kebutuhan Informasi dan Pendidikan yang memberi nilai positif untuk semua kalangan masyarakat. Banyaknya operator yang menawarkan paket Internet tentunya akan membuat konsumen menjadi sulit menentukan pilihan yang tepat sesuai dengan keinginan dan kriterianya. Untuk mengatasi permasalahan tersebut maka dibut sebuah sistem yang akan mempermudah pengambilan keputusan untuk memilih paket layanan Internet, salah satunya yaitu dengan adanya decision support system untuk membantu masyarakat dalam memilih paket layanan Internet yang paling baik. Metode yang digunakan dalam penelitian ini adalah Metode ANP. Dengan metode ANP ini diharapkan dapat membantu masyarakat dalam menentukan alternatif-alternatif mana yang akan dipilih sebagai suatu keputusan akhir dalam Pemilihan Paket Internet sesuai kebutuhan
\end{abstract}

Keywords: ANP, SPK, Paket Layanan Internet Prabayar, DSS, Kriteria. 


\section{PENDAHULUAN}

Kebutuhan akan komunikasi dan kecepatan mendapatkan informasi membuat masyarakat mencari alat komunikasi yang mudah dan praktis. Salah satu sarana komunikasi yang mudah dan praktis adalah ponsel atau telepon genggam (handphone). Ponsel mempunyai dua sistem yaitu ponsel dengan simcard berbasis GSM (Global System for Mobile) dan CDMA (Code Division Multiple Access). Kartu GSM dibagi digolongkan menjadi dua yaitu GSMprabayar dan GSM pasca bayar. Kartu GSM prabayar ini cara kerjanya dengan pembayaran di awal dalam bentuk pembelian voucher pulsa yang akan digunakan sebagai pembayaran tarif telepon, sms, dan paket Internet. Sedangkan kartu GSM pasca bayar pembayaran dilakukan setelah penggunakan jasa komunikasi dan tagihan akan di akumulasi dalam kurun waktu satu bulan. Penggunaan kartu GSM prabayar ditujukan bagi masyarakat dengan kebutuhan komunikasi yang tidak terlalu tinggi, sedangkan kartu GSM pasca bayar diperuntukan bagi pengguna jasa komunikasi dengan kebutuhan yang tinggi [1].

Menurut [2] dan [3], metode ANP mempunyai keunggulan dibandingkan dengan AHP dalam menyelesaikan masalah yang lebih kompleks. Dimana ANP sistem pendukung keputusan ini akan membantu melakukan penilaian produk yang berguna untuk memudahkan pengambilan keputusan dalam memilih produk layanan Internet terbaik dan paling layak untuk dipilihDi era perekonomian sekarang ini dalam bisnis semakin ketat dilakukan oleh Perusahaan. Perusahaan akan melakukan berbagai cara untuk menarik sebanyak mungkin konsumen membeli produknya. Strateginya adalah dengan melakukan atau menciptakan inovasi produk dan kemasan yang bisa membuat konsumen menjadi tertarik untuk membelinya.

\section{METODOLOGI PENELITIAN}

Beberapa penelitian terdahulu mengenai penelitian ini telah banyak dilaksanakan, diantaranya adalah:

a) Pengaruh Atribut Produk Terhadap Preferensi Konsumen dan Keputusan Pembelian Kartu Seluler Simpati [1], peneliti membahas pengaruh atribut produk terhadap keputusan pembelian produk layanan Internet terbaik.

b) Sistem Pendukung Keputusan Pemilihan Paket Internet Operator Telekomunikasi Dengan Metode AHP [4], peneliti membahas bagaimana Metode AHP memilih dan mengambil keputusan yang terbaik dalam Pemilihan Paket Internet Operator Telekomunikasi.

c) Perbandingan Penggunaan Metode AHP dan SAW untuk Sistem Pendukung Keputusan Pemilihan Paket Layanan Internet [5], penelitian ini menjelaskan bagaimana Metode AHP bisa mengambil keputusan dalam memilih Paket Layanan Internet terbaik. 
d) Penerapan Metode Analytical Hierarcy Process (AHP) sebagai Pendukung Keputusan Dalam Menentukan Internet Service Provider Terbaik di Pangkalpinang [6], dalam penelitian ini peneliti membahas penelitan mengenai bagaimana masyarakat bisa menentukan Internet Service Provider terbaik Dengan Metode AHP.

Penelitian terdahulu yang sudah dilakukan oleh beberapa peneliti merupakan referensi peneliti kembali dalam membuat penelitian menggunakan Metode ANP. Software yang dipergunakan dalam penelitian ini adalah Super Decisions yang mempermudah penggunanya dalam menentukan hasil terbaik dalam penelitian ini.

\subsection{Pengertian Internet dan Internet Service Provider (ISP)}

ISP (Internet Service Provider) yang dalam istilah Indonesia adalah Penyedia Jasa Internet, yakni suatu lembaga atau perusahaan yang menghubungkan komputer pengguna dengan Internet. Kebanyakan operator telekomunikasi adalah ISP. Pada umumnya Internet merupakan salah satu teknologi yang sangat pesat perkembangannya dan sudah merupakan simbol dari cara berkomunikasi secara bebas, tanpa dibatasi ruang, jarak dan waktu. Dengan ditunjang oleh kelebihan yang dimiliki oleh Internet, diantaranya bisa koneksi yang relatif terjangkau dan ketersediaan informasi yang tidak terbatas, Internet kini menjadi alternatif utama untuk memenuhi segala kebutuhan terutama kebutuhan akan informasi dan pendidikan yang akan memberi nilai positif untuk semua aktifitas. Namun demikian sudah banyak layanan Internet yang bisa digunakan untuk membantu memudahkan pengguna dalam mengakses Internet. Banyak kemudahan dan kelebihan yang mereka tawarkan. Layanan Internet itu sendiri adalah hubungan antar berbagai jenis komputer dan jaringan di dunia yang berbeda sistem operasi maupun aplikasinya dimana hubungan tersebut memanfaatkan kemajuan media komunikasi (telepondan satelit) yang menggunakan protokol standar dalam berkomunikasi yaitu protokol TCP/IP yang berisikan informasi [6].

\subsection{Metode ANP}

Metode Analytical Network Process adalah hubungan antara kelompok individu pada tingkat hirarki yang berbeda serta interaksi antara kriteria dan sub kriteria untuk mendapatkan hasil yang akurat dan efisien [3] dan Metode Analytic Process (ANP) merupakan pengembangan metode Analytic Hierarchy Process (AHP). Metode ANP mampu memperbaiki kelemahan metode AHP berupa kemampuan merekomendasikan keterkaitan pada metode ANP [2].

\subsection{Tahapan Metode ANP}

Menurut [7] dalam Jurnal [8], tahapan proses atau langkah-langkah dalam menyelesaikan permasalahan dengan menggunakan metode ANP adalah sebagai berikut :

a. Defenisikan masalah dan menentukan kriteria solusi yang diinginkan. 
b. Tentukan pembobotan komponen dari sudut pandang managerial.

c. Buat matriks perbandingan berpasangan yang menggambarkan kontribusi atau pengaruh setiap elemen atas setiap kriteria. Perbandingan dilakukan berdasarkan penilaian dari pengambil keputusan dengan menilai tingkat kepentingan suatu elemen.

d. Hitung eigenvector pembobotan

$$
\left[\begin{array}{r}
e_{1}=b_{1} / \sum_{i=1}^{n} b_{i} \\
e_{2}=b_{1} / \sum_{i=1}^{n} b_{i} \\
\ldots \\
e_{i}=b_{1} / \sum_{i=1}^{n} b_{i}
\end{array}\right]
$$

Keterangan : $e_{i}=$ menyatakan elemen matriks $\mathrm{E}$ baris ke-i.

e. Menghitung konsistensi yang diperoleh, apabila nilai kurang dari $10 \%$ maka nilai tersebut dapat dikatakan konsisten.

$$
\begin{aligned}
& C I=\frac{\lambda \max -n}{n-1}, \\
& C R=C I / R C I
\end{aligned}
$$

keterangan :

CI = consistensi index (indeks konsistensi)

$n \quad=$ orde dari matriks

$\lambda \max =$ nilai eigenvector terbesar dari matriks ber-ordo $n$.

$R I=$ random index (index acak) untuks setiap matriks ber-ordo $n$.

f. Ulangi langkah 3, 4, dan 5 untuk semua kriteria.yang ada.

g. Kemudian buat unwaighted supermatrik yaitu dengan cara memasukkan semua eigenvector yang telah dihitung pada langkah 5 kedalam sebuah supermatriks.

h. Langkah selanjutanya adalah membuat weighted supermatrik dengan cara melakukan perkalian setiap isi unwaighted supermatrik terhadap matriks perbandingan kriteria (kluster matrik).

$$
W_{w}=T_{z} \cdot W
$$

Keterangan :

$W_{w} \quad=$ Waighted supermatrik.

$T_{Z} \quad=$ Matrik perbandingan.

$W \quad=$ Unwaighted supermatrik

i. Membuat limiting supermatriks dengan cara memangkatkan supermatriks secara terus menerus hingga angka disetiap kolom dalam satu baris sama besar, setelah itu lakukan normalisasi terhadap limiting supermatriks.

$$
\lim _{k \rightarrow \infty} w^{k} \text { [2] }
$$

j. Ambil nilai dari alternatif yang dibandingkan kemudian lakukan normalisasi untuk mengetahui hasil akhir perhitungan. 


\subsection{Prinsip Dasar Analytic Network Process ( ANP )}

Dalam model ANP terdapat hubungan ketergantungan yang saling mempengaruhi satu sama lain. Adapun proses pemecahan yang dilakukan tanpa memandang masalah sebagai suatu sistem dengan suatu struktur tertentu adalah dengan cara [10-12] yaitu:

\section{a. Melakukan penilaian kriteria dan alternatif}

Penilaan kriteria dan alternatif dilakukan dengan melakukan perbandingan berpasangan.

\section{b. Melakukan Synthesis of Priority}

Synthesis of Priority dilakukan dengan menggunakan eigen vector method untuk mendapatkan bobot relatif bagi unsur - unsur pengambilan keputusan.

\section{c. Melakukan Logical Consistency}

Logical Consistency merupakan karakteristik penting dari ANP. Hal ini dicapai dengan mengagresikan seluruh eigen vector yang diperoleh dari berbagai tingkatan hirarki dan selanjutnya diperoleh suatu vector composive tertimbang yang menghasilkan urutan pengambilan keputusan.

Tabel 1. Matriks Perbandingan Berpasangan

\begin{tabular}{|c|c|c|c|c|}
\hline & $\mathrm{A} 1$ & $\mathrm{~A} 2$ & & $\mathrm{An}$ \\
\hline $\mathrm{A} 1$ & $\mathrm{~A} 11$ & $\mathrm{~A} 12$ & $\ldots \ldots$ & $\mathrm{A} 1 \mathrm{n}$ \\
\hline $\mathrm{A} 2$ & $\mathrm{~A} 21$ & $\mathrm{~A} 22$ & $\ldots \ldots$. & $\mathrm{A} 2 \mathrm{n}$ \\
\hline$\ldots \ldots$ & $\ldots \ldots .$. & $\ldots \ldots$ & $\ldots \ldots$ & $\ldots \ldots$ \\
\hline $\mathrm{An}$ & $\mathrm{Amn}$ & $\mathrm{An} 2$ & $\ldots \ldots$. & $\mathrm{Ann}$ \\
\hline
\end{tabular}

Berdasarkan tabel di atas kita dapat menentukan skala perbandingan antar elemen dalam proses pengambilan keputusan. Nilai B11 adalah nilai perbandingan elemen B1 (baris) terhadap B1 (kolom) yang menyatakan hubungan:

1. Seberapa jauh tingkat kepentingan B1 (baris) terhadap kriteria dibandingkan dengan B1 (kolom)

2. Seberapa jauh dominal B1 ( baris ) terhadap B1 (kolom)

3. Seberapa banyak sifat kriteria terhadap pada B1 (baris) dibandingkan dengan B1 (kolom). Nilai numerik yang dikenakan untuk seluruh perbandingan diperoleh dari skala perbandingan 1 sampai 9 yang telah ditetapkan oleh Saaty, seperti pada tabel 2

Tabel 2. Penilaian Perbandingan Berpasangan

\begin{tabular}{|c|l|}
\hline $\begin{array}{c}\text { Tingkat } \\
\text { Kepentingan }\end{array}$ & \multicolumn{1}{c|}{ Definisi } \\
\hline $\mathbf{1}$ & Sama pentingnya dibanding yang lain \\
\hline $\mathbf{3}$ & Modern (cukup) pentingnya dibanding yang lain \\
\hline $\mathbf{5}$ & Kuat pentingnya dibanding yang lain \\
\hline $\mathbf{7}$ & Sangat kuat pentingnya dibanding yang lain \\
\hline $\mathbf{9}$ & Ekstrim pentingnya dibanding yang lain \\
\hline
\end{tabular}




\begin{tabular}{|c|l|}
\hline $\begin{array}{c}\text { Tingkat } \\
\text { Kepentingan }\end{array}$ & \multicolumn{1}{c|}{ Definisi } \\
\hline $\mathbf{2 , 4 , 6 , 8}$ & Nilai dimana dua nilai yang berdekatan \\
\hline Resiprokal & $\begin{array}{l}\text { Jika elemen i memiliki salah satu angka diatas ketika } \\
\text { dibandingkan elemen j, maka j memiliki kebalikannya } \\
\text { ketika disbanding elemen i }\end{array}$ \\
\hline
\end{tabular}

\section{HASIL DAN PEMBAHASAN}

Adapun objek-objek dalam penelitian ini adalah :

a. Tujuan

Dalam penelitian ini tujuannya adalah membantu konsumen dalam memilih paket internet prabayar yang terbaik.

b. Kriteria

Kriteria dalam penelitian ini adalah :

1) Biaya

2) Kebutuhan

3) Kualitas Sinyal

4) Kecepatan

5) Kemudahan Mendapatkan Produk

c. Sub Kriteria

Sub Kriteria dalam penelitian ini adalah :

1) Mahal

2) Murah

3) Penting

4) Tidak Penting

5) Bagus

6) Tidak Bagus

7) Sangat Cepat

8) Kurang Cepat

9) Mudah didapat

10) Tidak mudah didapat

11) Alternative

d. Alternatif pada penelitian ini yaitu :

1) Indosat

2) Telkomsel

3) Axis

4) Tri

5) XL Axiata

6) SmartFren

Dalam Penelitian ini dilaksanakan survey dan tanya jawab ke beberapa Counter Penjualan Paket Internet dan pengguna paket prabayar yang ada di Medan. 


\subsection{Pengujian Dengan Menggunakan Tools Superdecision}

Dalam membuat program ini di Tools Superdecision, pertama adalah membuat cluster dan node di suatu cluster dimana setelah semuanya terbentuk kemudian klik save, seperti terlihat pada gambar 1:

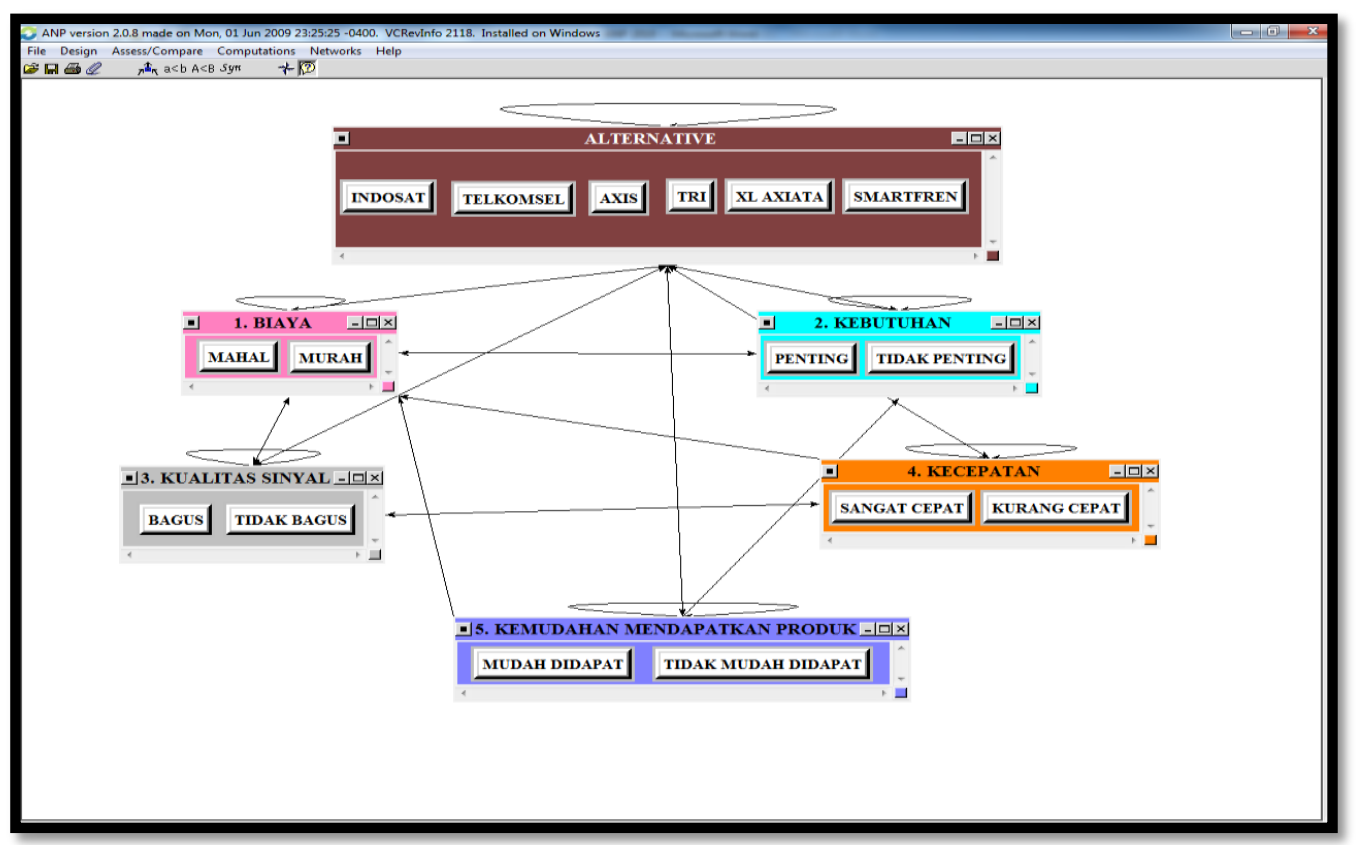

Gambar 1. Membuat Node didalam Cluster

Langkah berikutnya adalah dihubungkan node node yang ada dalam cluster alternatives. Selanjutnya pilih node connexions form, kemudian pilih node yang akan dihubungkan dan klik ok seperti terlihat pada gambar 2

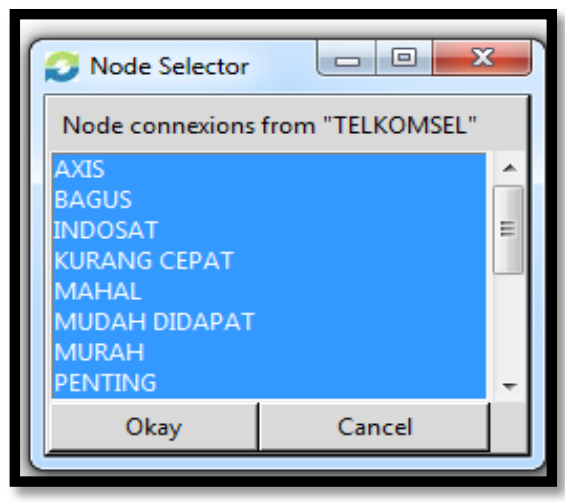

Gambar 2. Menghubungkan masing-masing Cluster

Kemudian semua cluster dikoneksikan dan hasil koneksi dari semua cluster yang telah terbentuk. Masukkan nilai dari kuesioner yang telah dirata-ratakan serta masukkan seluruh cluster yang sudah dikoneksikan pada tab menu matrix seperti gambar 3 dan 4 


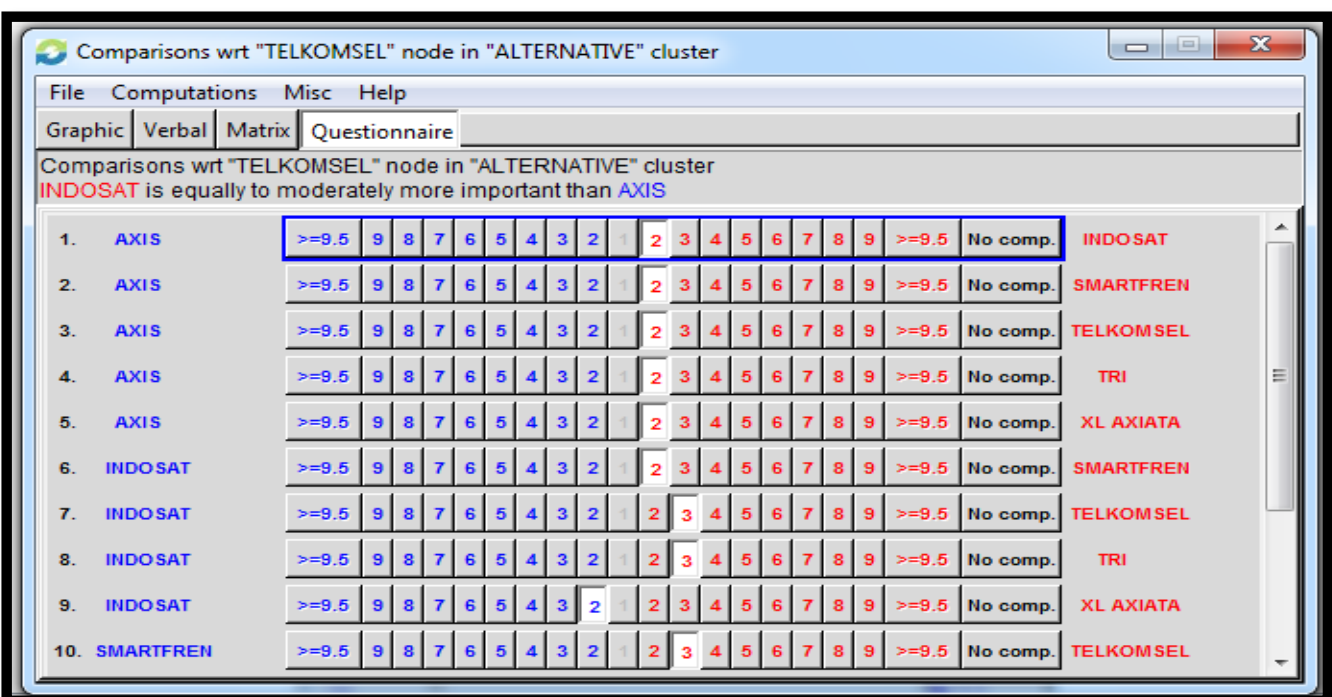

Gambar 3. Kuesioner Responden dalam perbandingan berpasangan

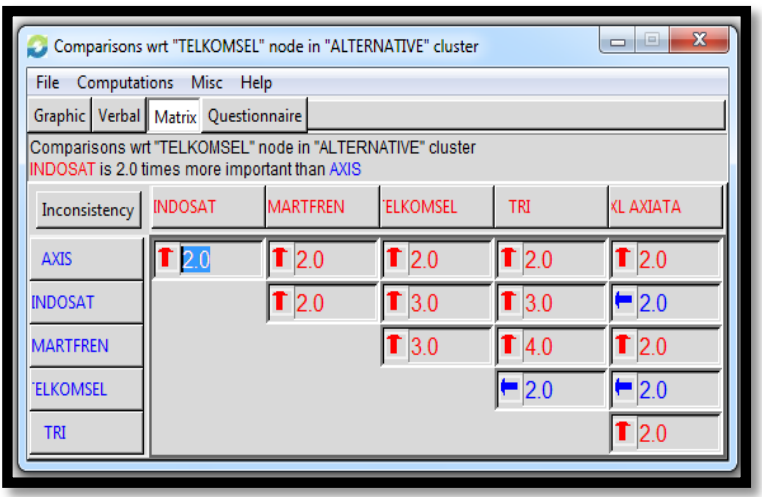

Gambar 4. Hasil Matrix

Setelah semua nilai dari hasil kuesioner dimasukkan, untuk mengetahui nilai prioritas tiap kriteria, klik computations lalu pilih ideal prioritas.

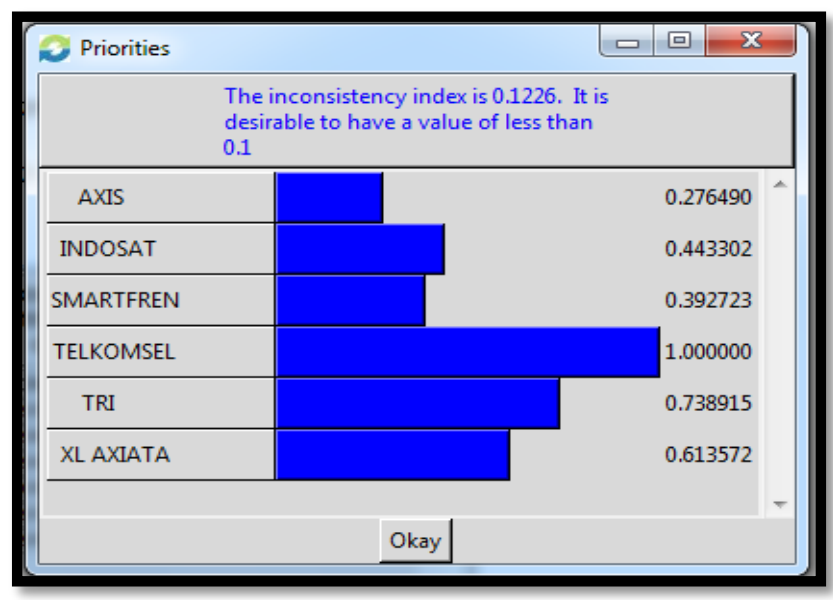

Gambar 5. Tampilan nilai prioritas 
Menganalisa hasil komputasi ANP dengan menampilkan rasio konsistensi perbandingan nilai matriks dalam setiap cluster yang ada dapat dilihat pada gambar 6

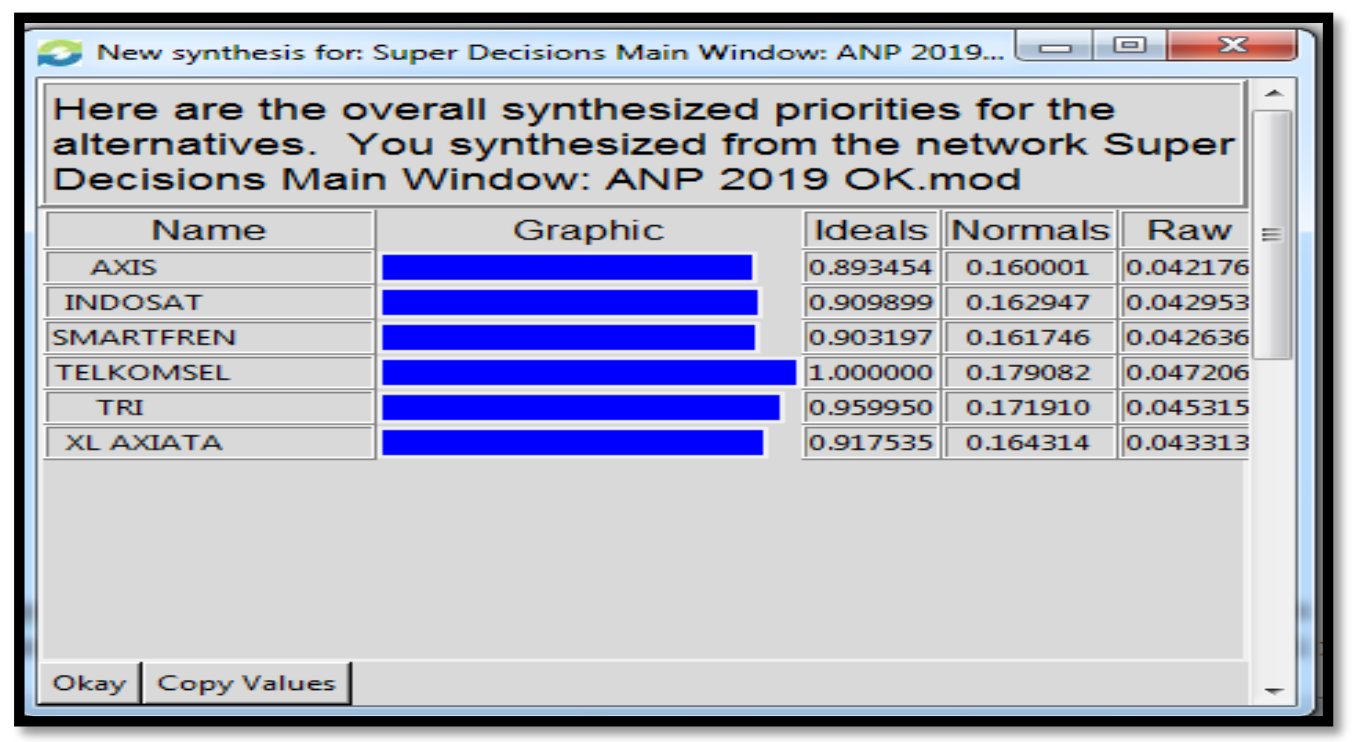

Gambar 6. Hasil Akhir

Gambar 7 adalah menampilkan laporan lengkap dari semua hasil analisa yang dilakukan di superdecision. Adapun langkah-langkah yang akan dilakukan adalah dengan klik menu computations, full report.

\section{Report for toplevel}

This is a report for how alternatives fed up through the system to give us our synthesized values. Return to main menu.

\section{Alternative Rankings}

\begin{tabular}{||c||c||c||c|c|c||}
\hline Graphic & Alternatives & Total & Normal & Ideal & Ranking \\
\hline \hline \hline & AXIS & 0.0422 & 0.1600 & 0.8935 & 6 \\
\hline \hline & INDOSAT & 0.0430 & 0.1629 & 0.9099 & 4 \\
\hline \hline & SMARTFREN & 0.0426 & 0.1617 & 0.9032 & 5 \\
\hline \hline & TELKOMSEL & 0.0472 & 0.1791 & 1.0000 & 1 \\
\hline \hline & TRI & 0.0453 & 0.1719 & 0.9599 & 2 \\
\hline \hline & XL AXIATA & 0.0433 & 0.1643 & 0.9175 & 3 \\
\hline \hline
\end{tabular}

Gambar 7. Laporan Lengkap Hasil Rangking

\section{SIMPULAN}

Adapun kesimpulan yang didapat dari penelitian ini adalah :

a. Kriteria - kriteria yang digunakan dalam penelitian ini yaitu Biaya, Kebutuhan, Kualitas Sinyal, Kecepatan dan Kemudahan Mendapatkan Produk. 
b. Dari hasil Perhitungan didapat hasil Telkomsel 17,91 \%, Tri 17,19\%, XL Axiata 16,43 \% , Indosat 16,29 \% , SmartFren 16,17 \% dan Axis $16,00 \%$.

\section{UCAPAN TERIMA KASIH}

Penulis mengucapkan terima kasih kepada Kementerian Riset, Teknologi dan Pendidikan Tinggi Republik Indonesia (Ristekdikti) yang telah membantu penulis dalam penelitian ini

\section{DAFTAR PUSTAKA}

[1] Dya, et. al (2016), “ Pengaruh Atribut Produk Terhadap Preferensi Konsumen Dan Keputusan Pembelian Kartu Seluler Simpati”, Jurnal Administrasi Bisnis (JAB) Volume 38 No 1, September 2016.

[2] Ratih Adinda Destari (2016) " Sistem Rangking Pemanfaatan Susu Bayi Menggunakan Analytical Network Process (ANP) “, Jurnal Ilmiah SISFOTENIKA Vol.6, No. 1, Januari 2016.

[3] Asbon, et.al, (2017), " Improvement Accuracy Of Oil Meal Packaging With Method ANP “ , International Conference on Cyber and IT Service Management (CITSM), Agustus 2017.

[4] Bagus, et.al (2013), " Sistem Pendukung Keputusan Pemilihan Paket Internet Operator Telekomunikasi Dengan Metode AHP (Analytical Hierarchy Process) ", Jurnal TIKomSIN, ISSN 2338-4018, Tahun 2013.

[5] Dian dan Sari (2012), " Perbandingan Penggunaan Metode AHP dan SAW Untuk Sistem Pendukung Keputusan Pemilihan Paket Layanan Internet ", Jurnal ITSMART Vol. 1, No. 2, Desember 2012

[6] Yogi dan Hilya (2016), " Penerapan Metode Analytical Hierarchy Process (AHP) Sebagai Pendukung Keputusan Dalam Menentukan Internet Service Provider Terbaik di Pangkalpinang “, Jurnal SISFOKOM Volume. 05, Nomor. 01, Maret 2016

[7] Fitriyani, et.al (2017), " Penerapan Algoritma Euclidean Distance Untuk Pemilihan Paket Internet Berdasarkan Wilayah “, Jurnal PROGRESIF Vol. 13, No. 1, Februari 2017.

[8] Pungkasanti, et.al, (2017) "Application of Analytic Network Process (ANP) On Decision Support System ", TRANSFORMATICS Journal, Volume 14, Number 2, January 2017.

[9] Wang, et.al, (2015) “ A Rating Based Analytic Network Process (F-ANP) Model for Evaluation of Ship Maneuverability “, Ocean Engineering, 106:39-46, 2015.

[10]Asbon Hendra (2015), " Pemilihan Media Promosi Dengan Menggunakan Analytical Network Process (ANP)", IT Journal. Vol.3 No. 2, Oktober 2015, hlm. $135-145$.

[11]Asbon, et.al, (2018), "Improvement Accuracy Of Instant Noodle Product Selection With Method ANP ", International Conference on Cyber and IT Service Management (CITSM), Agustus 2018.

[12]Ratih Adinda Destari, et.al, (2018), “ Application Of ANP Methods For Selecting The Best Bread Product ", International Conference on Cyber and IT Service Management (CITSM), Agustus 2018. 